\title{
Extreme Precipitation Estimation with Typhoon Morakot Using Frequency and Spatial Analysis
}

\author{
Hone-Jay Chu ${ }^{1}$, Tsung-Yi Pan ${ }^{2, *}$, and Jun-Jih Liou ${ }^{3}$ \\ ${ }^{1}$ Department of Geomatics, National Cheng-Kung University, Tainan, Taiwan, ROC \\ ${ }^{2}$ Center for Weather Climate and Disaster Research, National Taiwan University, Taipei, Taiwan, ROC \\ ${ }^{3}$ National Science and Technology Center for Disaster Reduction, Taipei, Taiwan, ROC
}

Received 28 January 2011, accepted 10 May 2011

\begin{abstract}
Typhoon Morakot lashed Taiwan and produced copious amounts of precipitation in 2009. From the point view of hydrological statistics, the impact of the precipitation from typhoon Morakot using a frequency analysis can be analyzed and discussed. The frequency curve, which was fitted mathematically to historical observed data, can be used to estimate the probability of exceedance for runoff events of a certain magnitude. The study integrates frequency analysis and spatial analysis to assess the effect of Typhoon Morakot event on rainfall frequency in the Gaoping River basin of southern Taiwan. First, extreme rainfall data are collected at sixteen stations for durations of 1, 3, 6, 12, and 24 hours and then an appropriate probability distribution was selected to analyze the impact of the extreme hydrological event. Spatial rainfall patterns for a return period of 200-yr with 24-hr duration with and without Typhoon Morakot are estimated. Results show that the rainfall amount is significantly different with long duration with and without the event for frequency analysis. Furthermore, spatial analysis shows that extreme rainfall for a return period of $200-\mathrm{yr}$ is highly dependent on topography and is smaller in the southwest than that in the east. The results not only demonstrate the distinct effect of Typhoon Morakot on frequency analysis, but also could provide reference in future planning of hydrological engineering.
\end{abstract}

Key words: Typhoon Morakot, Frequency analysis, Spatial analysis, Precipitation

Citation: Chu, H. J., T. Y. Pan, and J. J. Liou, 2011: Extreme precipitation estimation with Typhoon Morakot using frequency and spatial analysis. Terr. Atmos. Ocean. Sci., 22, 549-558, doi: 10.3319/TAO.2011.05.10.02(TM)

\section{INTRODUCTION}

Typhoon Morakot struck Taiwan from 7 - 9 August 2009 and caused record?breaking rainfall in southern Taiwan. Typhoon Morakot wrought catastrophic damage in Taiwan, leaving nearly 700 dead and roughly NT $\$ 110$ billion in damages. The storm produced copious amounts of rainfall, peaking at $2777 \mathrm{~mm}$, surpassing the previous record of $1736 \mathrm{~mm}$ set by Typhoon Herb in 1996 (Ge et al. 2010; Hong et al. 2010). The extreme amount of rainfall triggered enormous mudslides and severe flooding throughout southern Taiwan. Consequently, Typhoon Morakot led to the worst flooding in the last 50 years in Taiwan. After the event, the hydrologists and engineers examined the effect of precipitation from typhoon Morakot based upon a frequency analysis of monitoring and assessment.

\footnotetext{
* Corresponding author

E-mail: tsungyi.pan@gmail.com
}

The relationship between rainfall depth, intensity and duration to a return period based on historical observations is estimated by using precipitation frequency analysis. Such information is important for the analysis and design of flood control strategies in an urban environment (Young and McEnroe 2006). This study was initiated amid concern that the precipitation frequency estimates currently used for hydrological engineering design considering Typhoon Morakot may be outdated. Furthermore, several investigators have published evidence of upward trends in the frequency of intense rainfall. For example, Huff and Angel (1992) found that a 5-year, 24-hr rainfall depth increased 10\% from the period $1907-1947$ to the period $1948-1987$ for western Missouri (Young and McEnroe 2006). Karl and Knight (1998) demonstrated that annual precipitation has increased on the order of $10 \%$ across the United States, and they attributed most of this increase to a growth in the 
frequency and intensity of extreme events. In Europe, Fowler and Kilsby (2003) prsented a worldwide increase in both the frequency and intensity of heavy rainfall. Brunetti et al. (2000) demonstrated a strong trend in precipitation intensity during the last 60 - 80 years could be associated with an increase in the flood risk over Northern Italy. Zhai et al. (2005) analyzed the total precipitation and frequency of daily precipitation extremes over China, and demonstrated significant increases in extreme precipitation in the south China coastal area. However, unique precipitation characteristics of Taiwan is worthy of study because of extreme precipitation brought about by typhoons. Thus, the change of rainfall frequency curve will be highlighted after an extreme event, i.e., typhoon Morakot happens.

The purposes of this study are (a) to evaluate the differences of extreme precipitation for various return periods based on observed data with and without Typhoon Morakot, (b) to investigate the existence of trends in annual maximum precipitation for various durations in long-term planning, and (c) to detect spatial patterns in regional maximum precipitation data sets.

\section{METHOD}

The study integrates frequency and spatial analyses to qualify the impact of Typhoon Morakot, and the flowchart is shown in Fig. 1. First, historical rainfall observations are collected and then the appropriate probability distribution is used to analyze the effect of the hydrological extreme event. In addition, the patterns of extreme regional rainfall in the Gaoping River basin are estimated by kriging methods.

\subsection{Frequency Analysis}

Frequency analysis is used to predict design floods or precipitation for sites across a basin. The technique involves using observed annual peak discharge or rainfall data to calculate statistical information such as mean values, standard deviations, skewness, and recurrence intervals. These statistical data are then used to construct frequency distributions, which are graphs and tables that tell the likelihood of various discharges or rainfalls as a function of recurrence interval or exceedence probability.

The study modeled an annual maximum rainfall series by a log-Pearson Type 3 (LP3) distribution. The recommended technique is to use the method of moments to fit a Pearson Type 3 distribution to the base- 10 logarithms of the peaks, $\mathrm{Z}$, at selected exceedance probability by the equation:

$$
\log _{10} Z=\bar{Z}+K \times S
$$

where $\bar{Z}$ and $S$ are mean and standard deviation of the base-
10 logarithms of station data $(z) . K$ is a frequency factor that is a function of the skewness coefficient. Readers are referred to USGS (1982) for more details about properties of the frequency factor $K$ and calculation process of frequency analysis.

Estimators of the mean, standard deviation, and skew coefficient of the logarithms of the sample data are computed using traditional moment estimators (Adamowski and Bougadis 2003; Griffis and Stedinger 2007; Norbiato et al. 2007). The study follows Bulletin 17B guidelines of the Interagency Advisory Committee on Water Data (USGS 1982). The probability density function of the LP3 distribution, which is always a positively skewed one, is (USGS 1982; Haktanir et al. 2010):

$f(z)=\left[\frac{\ln (z)-c}{b}\right]^{a-1} \cdot \frac{\exp \{-[\ln (z)-c] / b\}}{z b \Gamma(a)}$

where $\Gamma$ is the gamma function. $a, b$ and $c$ are shape, scale, and location parameters, respectively. As $a$ and $b$ are positive real numbers, $c$ can be negative.

To establish a better understanding of the hydrological characteristics of Typhoon Morakot, rainfall frequency curves were derived in the study area.

\subsection{Spatial Analysis}

After determining the frequency curve at each station, spatial patterns could be estimated using a geostatistical approach. The study estimates the spatial patterns of extreme rainfall using kriging and examines the effect of Typhoon Morakot in the study area. Kriging is a linear re-

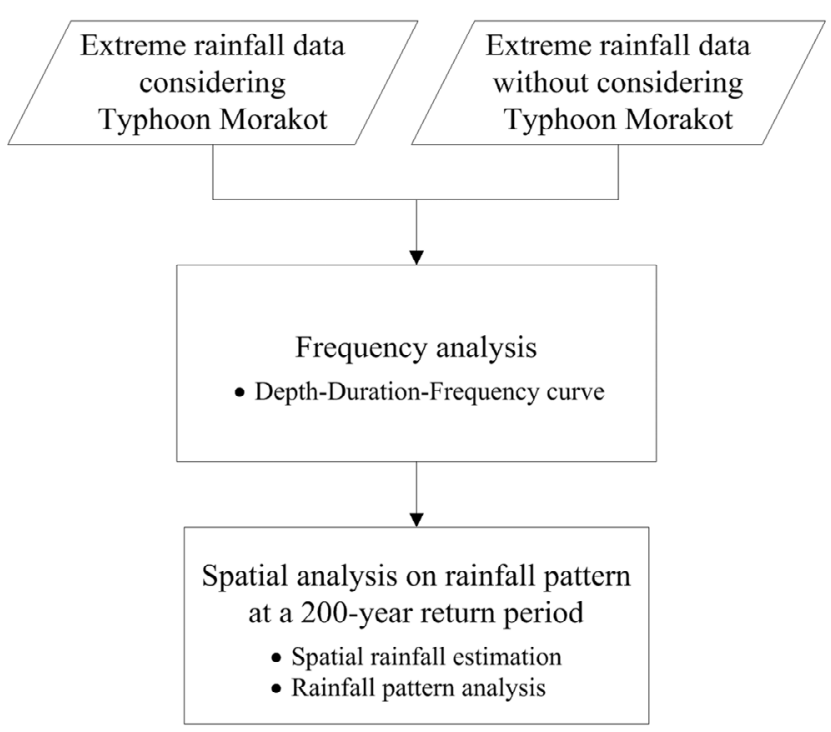

Fig. 1. The flowchart of the study. 
gression set of (Best Linear Unbiased Estimator) routines which minimize estimation variance from a predefined covariance model. Kriging is estimated using weighted sums of adjacent observed rainfalls. The weights depend on the correlation structure exhibited and are determined by minimizing estimated variance. Kriging provides a parametric distribution of rainfall in fields estimated at an unsampled location. The kriging models could be used to estimate the spatial patterns of rainfall without measuring all data in an entire area (Prudhomme and Reed 1999; Goovaerts 2000; Cheng et al. 2003; Lloyd 2005; Griffis and Stedinger 2007; Haberlandt 2007).

In this study, we applied ordinary kriging to interpolation of design rainfall depths, and therefore the theory of ordinary kriging is briefly described below. Let $Z(x)$ be a random variable defined at location $x$ and be a second-order stationary random field in a spatial domain. Under the second-order stationarity assumption, the spatial variation structure of $Z(x)$ is independent of spatial locations and is characterized by a semi-variogram defined as

$\gamma\left(\left|x_{i}-x_{j}\right|\right)=\frac{1}{2} \operatorname{Var}\left[Z\left(x_{i}\right)-Z\left(x_{j}\right)\right]=\frac{1}{2} E\left[Z\left(x_{i}\right)-Z\left(x_{j}\right)\right]^{2}$

We now attempt to estimate an unknown value of $Z$ at $x_{0}$, i.e., $z\left(x_{0}\right)$, using observed values $z\left(x_{i}\right), i=1,2, \ldots, m$, at neighboring locations and the following linear equation.

$\hat{z}\left(x_{0}\right)=\sum_{i=1}^{m} \lambda_{i} z\left(x_{i}\right)$

where $\lambda_{i}$ represents weights assigned to measurements $z\left(x_{i}\right)$. The ordinary kriging estimator is a best linear unbiased estimator (BLUE) that satisfies the following conditions:

$E\left[\hat{Z}\left(x_{0}\right)\right]=E\left[Z\left(x_{0}\right)\right]$

$\min \operatorname{Var}\left[\hat{Z}\left(x_{0}\right)\right]-\left[Z\left(x_{0}\right)\right]$

The unbiasedness condition of Eq. (4) is satisfied with unitsum weights:

$\sum_{i=1}^{m} \lambda_{i}=1$

Minimization of the variance of estimation error, under the constraint on $\sum_{i=1}^{m} \lambda_{i}=1$, is achieved by introducing a Lagrange multiplier $(\mu)$ and following the equation.

$\operatorname{Var}\left[\hat{Z}\left(x_{0}\right)\right]-\left[Z\left(x_{0}\right)\right]-2 \mu\left(\sum_{i=1}^{m} \lambda_{i}-1\right)$ with respect to $\lambda_{i}$ and $\mu$. The kriging in this study is performed by GSLIB (Deutsch and Journel 1992).

\section{STUDY AREA}

The Gaoping River is the largest river in Taiwan in terms of its drainage area $\left(3257 \mathrm{~km}^{2}\right)$ with an estimated mean annual runoff of $8.45 \times 10^{9} \mathrm{~m}^{3}$. Figure 2 shows the location and topography of the Gaoping River basin. The headwater of the river originates in the southern part of the Central Mountain Range near Mt. Jade whose elevation is $3997 \mathrm{~m}$ above the sea level. Based on the elevation, $47.45 \%$ of the drainage basin is above $1000 \mathrm{~m} ; 32.38 \%$ is between 100 and $1000 \mathrm{~m}$, and $20.17 \%$ is below $100 \mathrm{~m}$. Due to the northeast-southwest mountain ranges, the terrain slope lifting of the warm and moist air associated with typhoons or a converge of southwestern monsoon and typhoons, such as Morakot, often caused continuous torrential rainfall on the windward side leading to serious flooding (Lee et al. 2006). Therefore, the annual discharge of the Gaoping River is concentrated in the summer season and early fall (June to October), culminating in August (Liu et al. 2009).

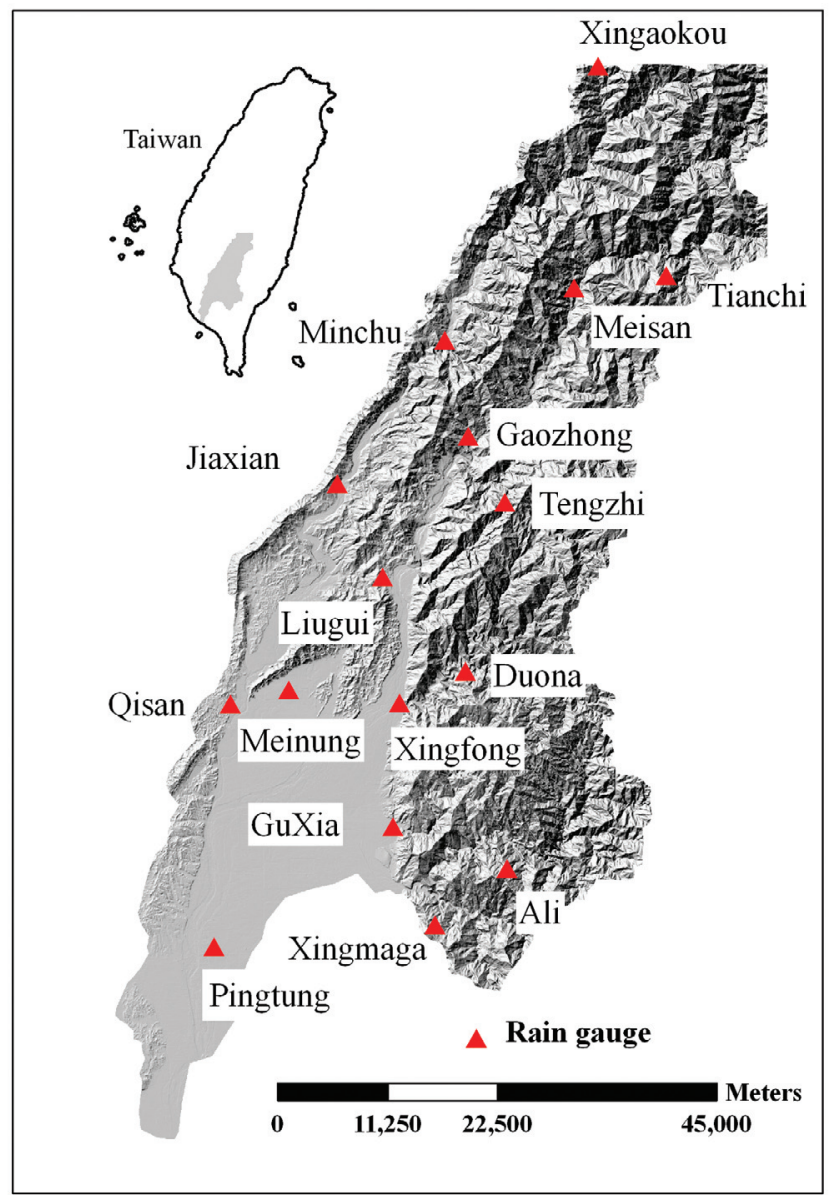

Fig. 2. The location and topography of the Gaoping River basin in southwestern Taiwan. 
In this study, 16 rain gauges in the Gaoping River basin are selected. The locations of the rain gauges are shown in Fig. 2. Table 1 lists the profile of the selected rain gauges. The elevations of rain gauges in Table 1 show the enormous variation from $25 \mathrm{~m}$ (Pingtung) to $2540 \mathrm{~m}$ (Xingaokou) of the topography of the Gaoping River basin. Additionally, the available observations of all rain gauges are over 25 years which satisfies the essential requirement of precipitation frequency analysis. The precipitation frequency analysis was performed based on the annual maximum rainfall series with $1,3,6,12$ and $24 \mathrm{hr}$ durations induced by typhoon's circulation.

\section{RESULTS AND DISCUSSION}

\subsection{Data Analysis}

The rainfall data used in this study represent the maximum 24-hr rainfall per year which is carried out through moving window method. Figure 3 shows the maximum rainfall estimation for a 24-hr duration during Typhoon Morakot in 2009. The rainfall patterns reveal that hotspot is near south-east part; and the area with high amounts of rainfall is close to the mountain area in the east. Thus, observation Xingmaga was selected as the primary analysis frequency. According to the top six annual maximum rainfalls in Xingmaga for different durations as shown in Table 2, the cumulative rainfalls of Typhoon Morakot are ranked 6th and 3 rd in the durations of 1 and 3 hours, respectively. However,

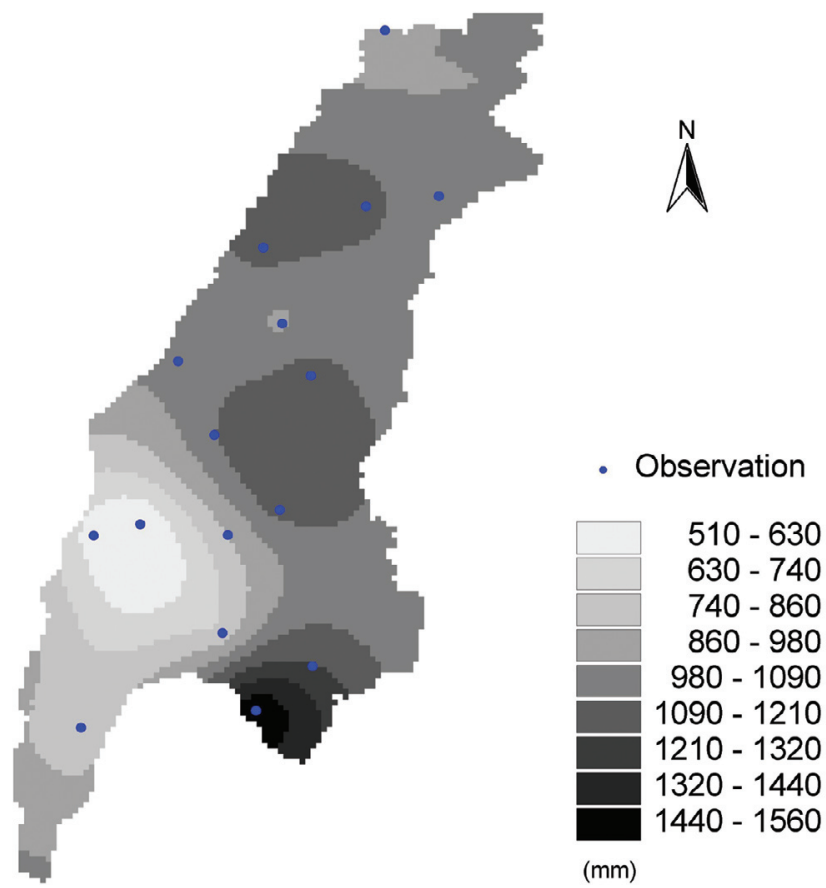

Fig. 3. Rainfall depth with a 24-hr duration during Typhoon Morakot.

Table 1. The profile of rain gauges in the Gaoping River basin.

\begin{tabular}{cc|cc|c|cc}
\hline \multicolumn{2}{c|}{ Rain gauge } & \multicolumn{2}{c|}{ Location (TM97) } & Elevation & \multicolumn{2}{c}{ Service life (year) } \\
\hline ID & Name & $\mathbf{X}$ & $\mathbf{Y}$ & $\mathbf{( m )}$ & Range & Total period \\
\hline 00P470 & Qisan & 195989 & 2531247 & 64 & $1961-2009$ & 49 \\
00Q070 & Pingtung & 194329 & 2506375 & 25 & $1956-2009$ & 54 \\
01M310 & Xingaokou & 233701 & 2596708 & 2540 & $1984-1990,1992-2009$ & 25 \\
01P260 & Duona & 220083 & 2534593 & 458 & $1967-2009$ & 43 \\
01P660 & Jiaxian & 206926 & 2553841 & 355 & $1957-2009$ & 53 \\
01P770 & Meinung & 201997 & 2532716 & 61 & $1958-2009$ & 52 \\
01Q160 & Xingfong & 213346 & 2531343 & 166 & $1957-2009$ & 53 \\
01Q610 & GuXia & 212659 & 2518653 & 144 & $1980-2009$ & 30 \\
01Q910 & Ali & 224338 & 2514330 & 1320 & $1967-2009$ & 43 \\
01Q920 & Xingmaga & 216985 & 2508583 & 750 & $1975-2009$ \\
01V010 & Gaozhong & 220387 & 2558743 & 520 & $1982-2009$ & 35 \\
01V040 & Liugui & 211606 & 2544300 & 259 & $1982-2009$ \\
01V050 & Tengzhi & 224105 & 2551973 & 1640 & $1980-2009$ & 27 \\
01V060 & Meisan & 231253 & 2573907 & 850 & $1980-2009$ & 28 \\
01V070 & Tianchi & 240671 & 2575231 & 2230 & $1978-2009$ & 30 \\
01V080 & Minchu & 217959 & 2568582 & 530 & $1978-2010$ & 30 \\
\hline
\end{tabular}


Table 2. The top six annual maximum rainfalls for 1, 3, 6, 12 and 24-hr durations in Xingmaga.

\begin{tabular}{c|cc|cc|cc|ccc|c}
\hline No. & Year & $\begin{array}{c}\text { 1-hr rainfall } \\
(\mathbf{m m})\end{array}$ & Year & $\begin{array}{c}\text { 3-hr rainfall } \\
(\mathbf{m m})\end{array}$ & Year & $\begin{array}{c}\text { 6-hr rainfall } \\
(\mathbf{m m})\end{array}$ & Year & $\begin{array}{c}\text { 12-hr rainfall } \\
(\mathbf{m m})\end{array}$ & $\begin{array}{c}\text { Year } \\
\text { (mm-hr rainfall } \\
(\mathbf{m m})\end{array}$ \\
\hline 1 & 1996 & 136.0 & 1996 & 384.0 & $\mathbf{2 0 0 9}$ & 585.0 & $\mathbf{2 0 0 9}$ & 1071.0 & $\mathbf{2 0 0 9}$ & 1897.0 \\
2 & 2007 & 134.0 & 2007 & 358.0 & 2007 & 578.0 & 2007 & 895.0 & 2005 & 1424.0 \\
3 & 1994 & 133.0 & $\mathbf{2 0 0 9}$ & 297.0 & 1996 & 571.0 & 2005 & 831.0 & 1989 & 1166.5 \\
4 & 1989 & 126.5 & 1994 & 295.5 & 2005 & 470.0 & 1989 & 819.5 & 2007 & 1121.0 \\
5 & 2006 & 120.0 & 1977 & 285.0 & 1989 & 433.5 & 1996 & 778.0 & 1996 & 979.0 \\
6 & $\mathbf{2 0 0 9}$ & 118.0 & 2006 & 263.0 & 1977 & 422.0 & 1992 & 606.5 & 1982 & 959.0 \\
\hline
\end{tabular}

the cumulative rainfalls noted at 6,12 and 24 hours in duration are the highest for the past 35 years. In addition, Fig. 4 shows the accumulated annual maximum rainfall for a 24-hr duration from observations at Xingmaga from 1975 to 2009. Result shows that the slope of the blue line is $540.6 \mathrm{~mm}$ $24-\mathrm{hr}^{-1}$ before 2004 but that of the red line is $1184.2 \mathrm{~mm}$ 24-hr-1 after 2004. The slope rises rapidly after 2004 and it indicates that the change point occurs in 2004. Recently, the annual maximum rainfall for long durations may change due to climate change. Several studies (e.g., Guttman et al. 1992; Karl and Knight 1998) have found increases in precipitation amounts across the USA and Canada in recent years, which can be attributed to climate change (Adamowski and Bougadis 2003). Global mean surface temperature rose by about $0.6^{\circ} \mathrm{C}$ during the last century (IPCC 2001). An increase in global temperature leads to the intensification of a hydrologic cycle, which, in turn, affects characteristics of extreme climatic events. However, climate change has various effects on geographically diverse regions (Mishra and Singh 2010).

\subsection{Frequency Analysis of Extreme Precipitation}

The rainfall frequency of various intensities and durations is used extensively in the design and management of water resources projects considering extreme rainfall events. The most common frequency analysis consists of developing a relationship between rainfall intensity, depth, duration and frequency (or return period) (Adamowski and Bougadis 2003).

Figure 5 provides a graph with the Bulletin 17B guideline and systematic frequency curves, the systematic peaks, and confidence limits for a duration of 24-hr considering with and without Typhoon Morakot at observations from Xingmaga. Results show that the rainfall at Xingmaga with regard to Typhoon Morakot with return periods of 200, 100, $20,10,5$ and 2 years are 2309.7, 2029.7, 1498.6, 1164.2, 914.6, and $569.7 \mathrm{~mm}$. Absent Typhoon Morakot data, the rainfall with return periods of $200,100,20,10,5$ and 2 years are $1917.5,1717.1,1318.7,1053.0,845.8$, and 543.8 $\mathrm{mm}$. Their changing ratios with various return periods are $20 \%, 18 \%, 14 \%, 11 \%, 8 \%$, and $5 \%$, respectively. Results show that the rainfall intensity increases with the return period from 2 to 200 years. The rainfall intensity is significantly higher considering Typhoon Morakot than that without Typhoon Morakot. When Typhoon Morakot lashed Taiwan, Xingmaga measured a 24-hr maximum cumulative rainfall of up to $1897 \mathrm{~mm}$ and the second one is $1424 \mathrm{~mm}$ observed in 2005, since 1975 . To compare the 24-hr maximum cumulative rainfall with the results of precipitation frequency analysis of Xingmaga, the observation is close to a 200-yr return period rainfall, 1917.5mm, based on 1975 -

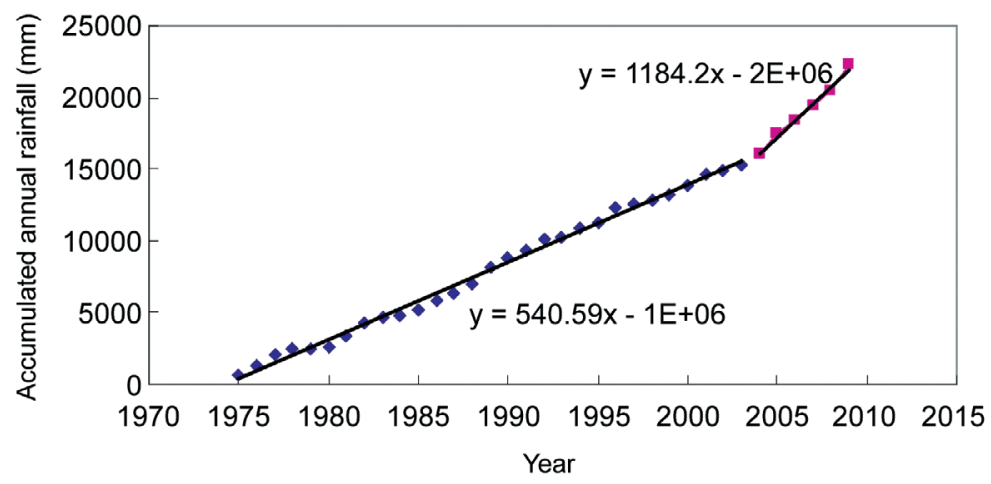

Fig. 4. Accumulated annual extreme rainfall for a 24-hr duration from Observation at Xingmaga. 

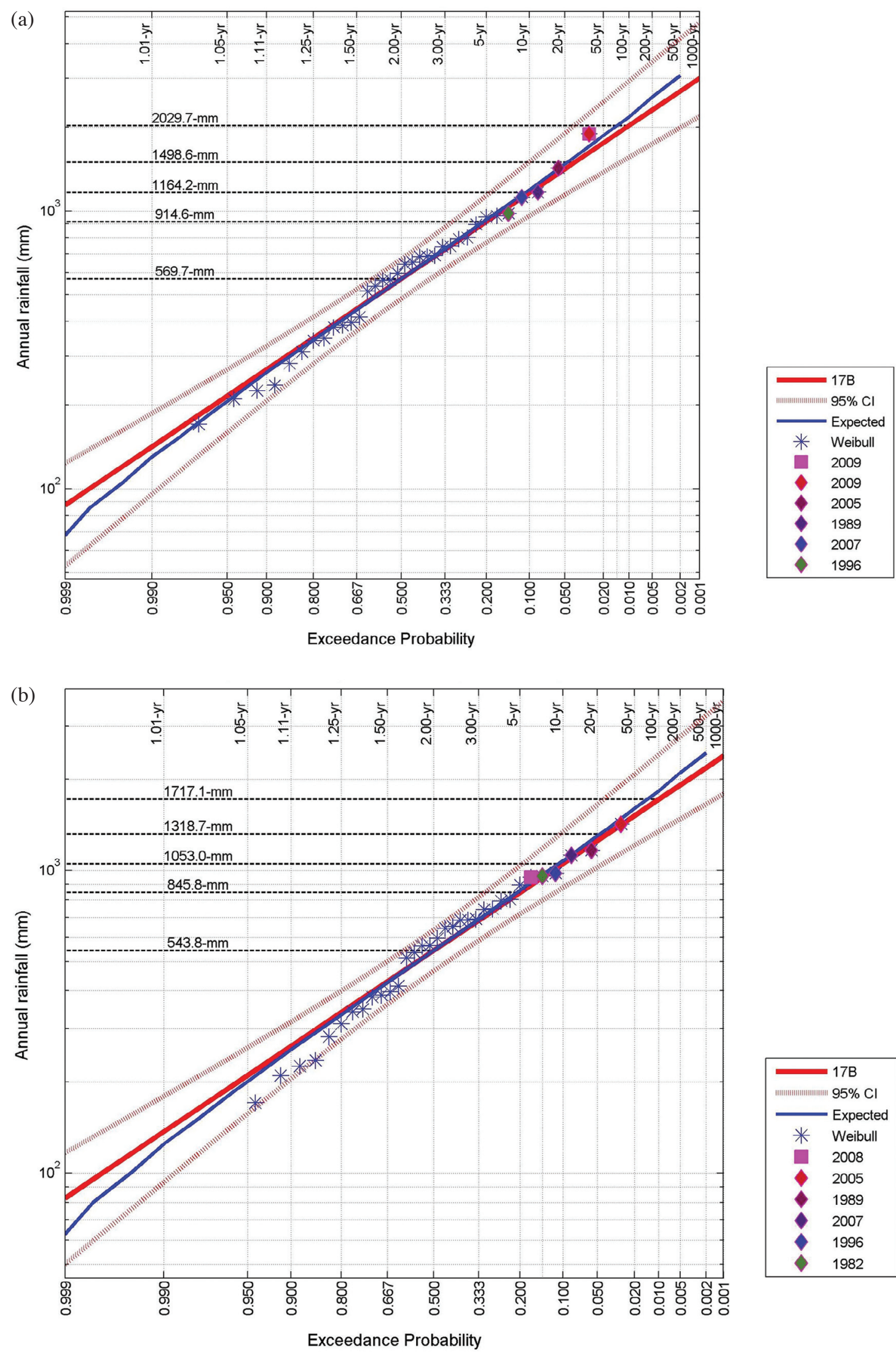

Fig. 5. Fitted curves of observed, expected peak rainfalls and the 95\% confidence intervals (dashed lines). (a) with Typhoon Morakot; (b) without Typhoon Morakot from observation at Xingmaga. 
2008 records (34 years). Moreover, the significant increase of a 200-yr return period 24-hr rainfall associated with Typhoon Morakot demonstrates the dominance of an extreme rainfall event with regard to a precipitation frequency analysis of the rain gauges with short service life.

Figures $6 \mathrm{a}$ and $\mathrm{b}$ display the depth-duration-frequency curves with and without Typhoon Morakot at the observation point of Xingmaga. Figure $6 \mathrm{c}$ is the difference ratio between the data with and without Typhoon Morakot. For the duration between 6,12 and 24 hours, the changing ratios are $8 \%, 12 \%$ and $20 \%$, respectively, in a $200-y r$ return period, and are $7 \%, 11 \%$ and $18 \%$, respectively, in a 100-yr return period. However, both changing ratios for 1 and $3 \mathrm{hr}$ durations are less than $4 \%$. The precipitation frequency analysis associated with Typhoon Morakot shows that the changing ratios are significant for the duration over 6 hours while they are slight for the durations of 1 and 3 hours.

\subsection{Spatial Analysis of Extreme Precipitation with and Without Typhoon Morakot}

Table 3 shows the effect of Typhoon Morakot on annual maximum precipitation for a 24-hr duration with a return period of 200 years in sixteen observations in south Taiwan. The annual extreme precipitation has increased at most to about $29 \%$ across the study area considering Typhoon Morakot, and they attributed most of those increases to a growth in the frequency and intensity of extreme events. Figure 7 shows the spatial maps based on a 24-hr extreme event with a return period of 200 years with and without
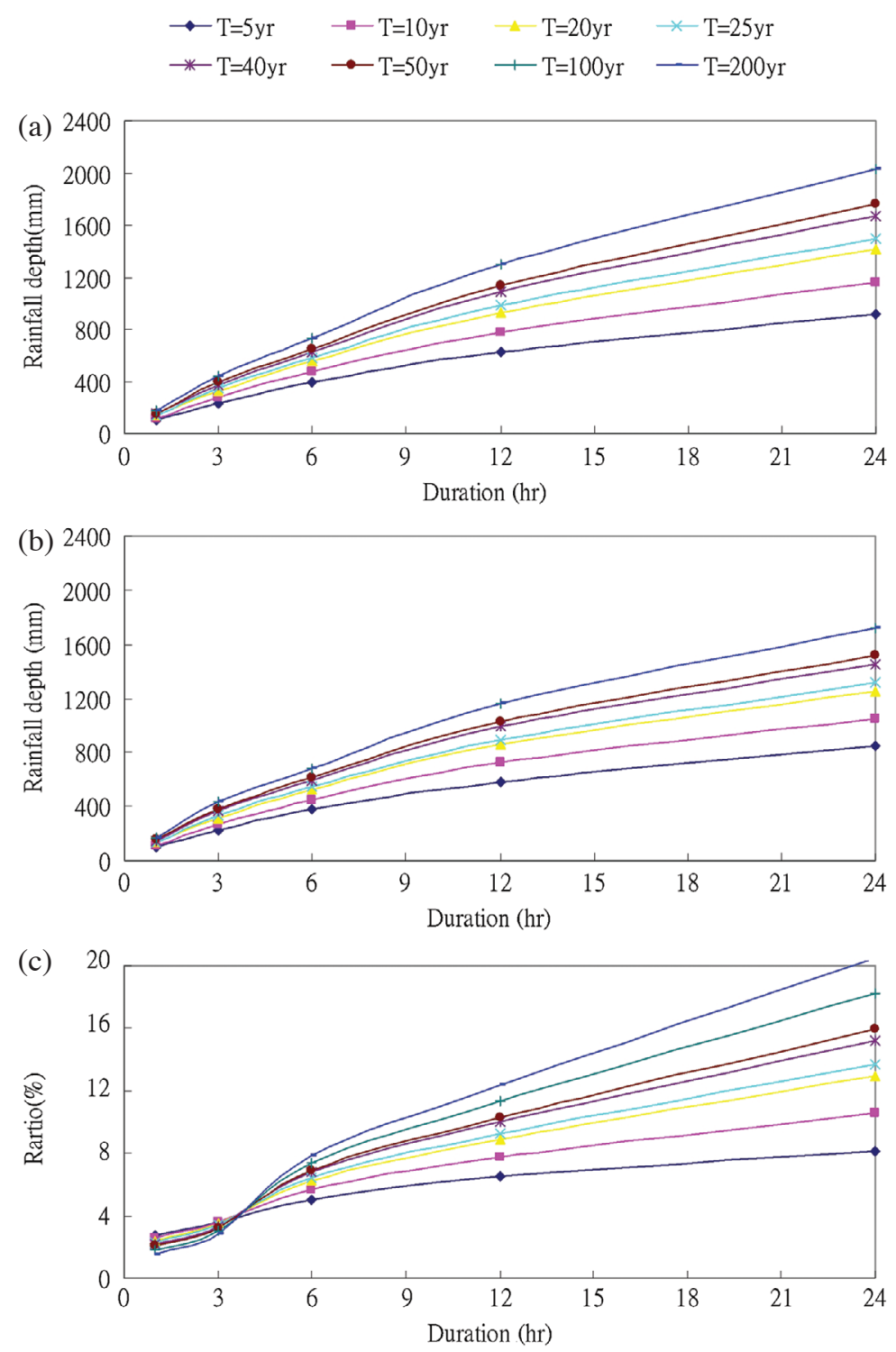

Fig. 6. Depth, duration, and frequency curves from observations at Xingmaga (a) with Typhoon Morakot; (b) without Typhoon Morakot; (c) the ratio difference between (a) and (b). 
Table 3. Annual maximum 24-hr rainfall at a return period of 200 years.

\begin{tabular}{|c|c|c|c|c|}
\hline \multirow{2}{*}{ Observation } & \multicolumn{2}{|c|}{ Maximum rainfall (mm) } & \multirow{2}{*}{ Difference (mm) } & \multirow{2}{*}{ Difference Ratio } \\
\hline & With Morakot & Without Morakot & & \\
\hline Xingmaga & 2295 & 1920 & 375 & $20 \%$ \\
\hline Ali & 1703 & 1590 & 113 & $7 \%$ \\
\hline Xingaokou & 1505 & 1358 & 147 & $11 \%$ \\
\hline Liugui & 1491 & 1227 & 264 & $22 \%$ \\
\hline Tengzhi & 1479 & 1192 & 287 & $24 \%$ \\
\hline Minchu & 1408 & 1091 & 317 & $29 \%$ \\
\hline Duona & 1333 & 1132 & 201 & $18 \%$ \\
\hline Meisan & 1285 & 1022 & 263 & $26 \%$ \\
\hline Gaozhong & 1253 & 1180 & 73 & $6 \%$ \\
\hline Tianchi & 1145 & 953 & 192 & $20 \%$ \\
\hline Jiaxian & 1098 & 937 & 161 & $17 \%$ \\
\hline Xingfong & 999 & 875 & 124 & $14 \%$ \\
\hline GuXia & 834 & 813 & 21 & $3 \%$ \\
\hline Pingtung & 780 & 715 & 65 & $9 \%$ \\
\hline Qisan & 710 & 679 & 31 & $5 \%$ \\
\hline Meinung & 680 & 680 & 0 & $0 \%$ \\
\hline
\end{tabular}
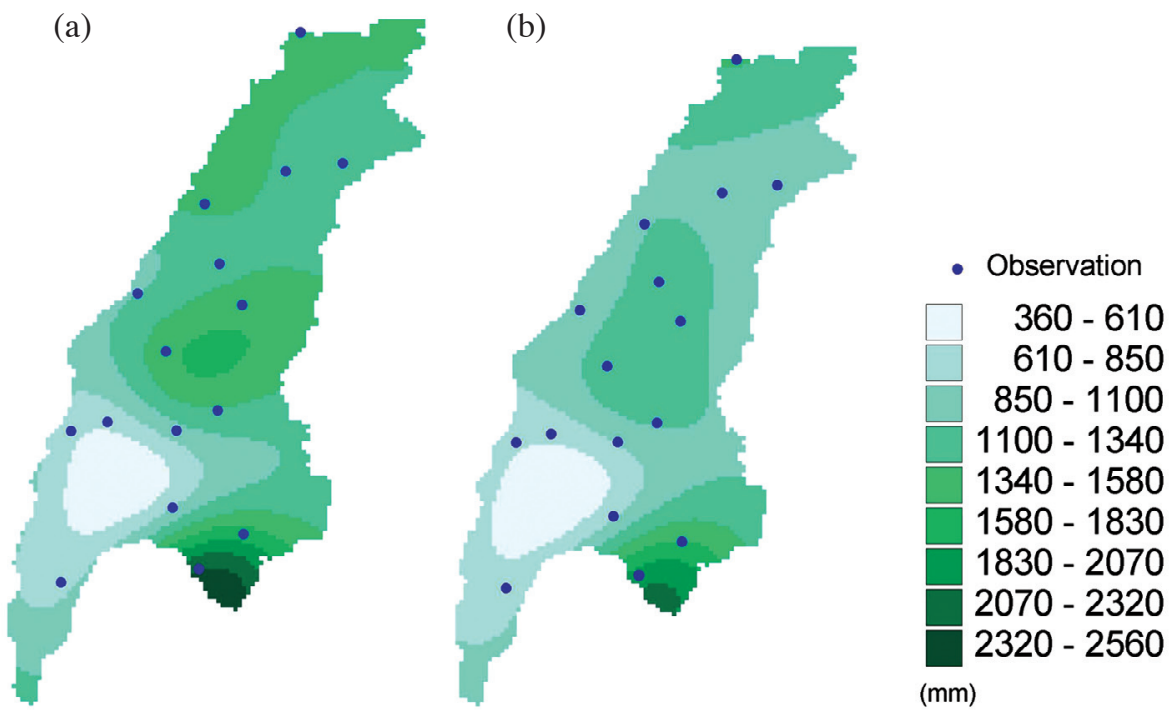

Fig. 7. Spatial maps of annual maximum rainfalls (a) with Typhoon Morakot; (b) without Typhoon Morakot.

Typhoon Morakot. Results indicate significant increases in the expected rainfall amount in the study area when considering the extreme event of Typhoon Morakot. The rainfall depth considering Typhoon Morakot is on average $164 \mathrm{~mm}$ higher than that without Typhoon Morakot. Figure 8 demonstrates the differences of spatial extreme rainfall maps ana- lyzed with and without Typhoon Morakot. The figure shows that the extreme rainfall difference is smaller in the southwest than that in the north-east. There is spatial variability in the mean annual rainfall, including a general increase in precipitation with elevation (Figs. 7 and 8). Furthermore, the increase of precipitation with elevation in the mountain 


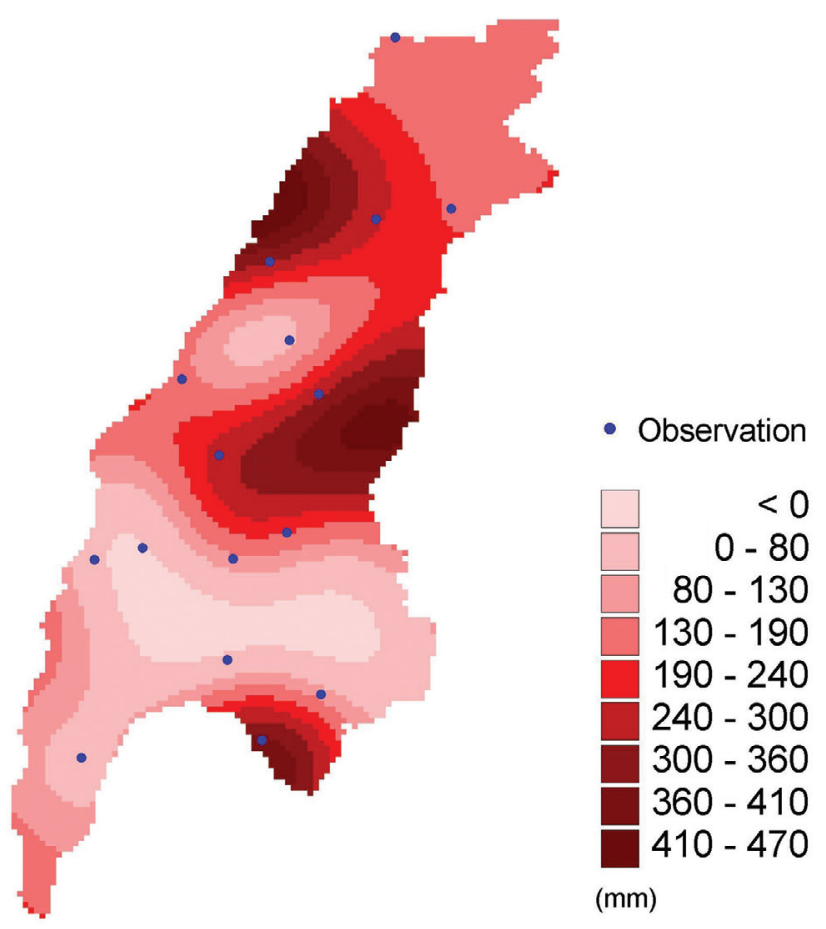

Fig. 8. Differences of annual maximum rainfall with and without Typhoon Morakot.

areas demonstrates the influence of landscape elevation on the variability and heterogeneity of precipitation. Over most of the southwest plain of the study area, the elevation ranges from 0 to $470 \mathrm{~m}$, and 24-hr extreme rainfall with a return period of 200 years varies under $1000 \mathrm{~mm}$. Consequently, the estimated extreme rainfalls are 1000 to $2300 \mathrm{~mm}$ surrounded by mountain ranges at high elevations over the northeast and along the eastern border, where the elevations range mostly near to $4000 \mathrm{~m}$.

\section{CONCLUSION}

Precipitation characteristics of Typhoon Morakot plays a crucial role in hydrological planning in southern Taiwan. In this study, a case study of the Gaoping River basin was presented. Based on the annual maximum data for the durations of 1, 3, 6, 12 and 24 hours, a generalized extreme value distribution was fitted to the extremes, and the spatial precipitation estimations were compared with and without Typhoon Morakot.

In short, the differences between the estimated precipitation based on the data with and without Typhoon Morakot are higher at long return periods with long durations (i.e., 12 and 24 hours) than that at short durations. Based upon frequency analysis results, the increase in precipitation depth causes a significant positive trend in considering precipitation contributed by Typhoon Morakot. Precipitation depth increases (e.g., $164 \mathrm{~mm}$ averagely in whole study area) for a 200-year event with 24-hr duration, especially in the mountain area.

Acknowledgements We are grateful to the Water Resources Agency and Central Weather Bureau in Taiwan for providing the monitoring data. We are also grateful to $\mathrm{Mr}$. Shao Kun Su for technical assistance in figure processing. Moreover, editors and anonymous reviewers made comments that improved this paper.

\section{REFERENCES}

Adamowski, K. and J. Bougadis, 2003: Detection of trends in annual extreme rainfall. Hydrol. Process., 17, 35473560, doi: 10.1002/hyp.1353. [Link]

Brunetti, M., L. Buffoni, M. Maugeri, and T. Nanni, 2000: Precipitation intensity trends in northern Italy. Int. J. Climatol., 20, 1017-1031, doi: 10.1002/1097-0088(20 0007)20:9<1017::AID-JOC515>3.0.CO;2-S. [Link]

Cheng, K. S., C. Wei, Y. B. Cheng, and H. C. Yeh, 2003: Effect of spatial variation characteristics on contouring of design storm depth. Hydrol. Process., 17, 17551769, doi: 10.1002/hyp.1209. [Link]

Deutsch, C. V. and A. G. Journel, 1992: GSLIB: Geostatistical Software Library and User's Guide, Oxford University Press, New York.

Fowler, H. J. and C. G. Kilsby, 2003: A regional frequency analysis of United Kingdom extreme rainfall from 1961 to 2000. Int. J. Climatol., 23, 1313-1334, doi: 10. 1002/joc.943. [Link]

Ge, X., T. Li, S. Zhang, and M. Peng, 2010: What causes the extremely heavy rainfall in Taiwan during Typhoon Morakot (2009)? Atmos. Sci. Lett., 11, 46-50, doi: 10.1002/asl.255. [Link]

Goovaerts, P., 2000: Geostatistical approaches for incorporating elevation into the spatial interpolation of rainfall. J. Hydrol., 228, 113-129, doi: 10.1016/S0022-16 94(00)00144-X. [Link]

Griffis, V. W. and J. R. Stedinger, 2007: Evolution of flood frequency analysis with Bulletin 17. J. Hydrol. Eng., 12,283-297, doi: 10.1061/(ASCE)1084-0699(2007)12: 3(283). [Link]

Guttman, N. B., J. R. Wallis, and J. R. M. Hosking, 1992: Regional temporal trends of precipitation quantiles in the US. Research Report RC 18453 (80774), IBM Research Division, Yorktown Heights, NY.

Haberlandt, U., 2007: Geostatistical interpolation of hourly precipitation from rain gauges and radar for a largescale extreme rainfall event. J. Hydrol., 332, 144-157, doi: 10.1016/j.jhydrol.2006.06.028. [Link]

Haktanir, T., M. Cobaner, and O. Kisi, 2010: Frequency analyses of annual extreme rainfall series from $5 \mathrm{~min}$ to 24 h. Hydrol. Process., 24, 3574-3588, doi: 10.1002/ hyp.7759. [Link] 
Hong, C. C., M. Y.Lee, H. H. Hsu, and J. L. Kuo, 2010: Role of submonthly disturbance and 40-50 day ISO on the extreme rainfall event associated with Typhoon Morakot (2009) in Southern Taiwan. Geophys. Res. Lett., 37, L08805, doi: 10.1029/2010GL042761. [Link]

Huff, F. A. and J. R. Angel, 1992: Rainfall frequency atlas of the Midwest. Illinois State Water Survey Bulletin 71, Midwestern Climate Center Research Report 9203.

IPCC (Intergovernmental Panel on Climate Change), 2001: Climate Change 2001: The Scientific Basis: Contribution of Working Group I to the Third Assessment Report of the Intergovernmental Panel on Climate Change, Cambridge University Press, New York.

Karl, T. R. and R. W. Knight, 1998: Secular trends in precipitation amount, frequency, and intensity in the United States. Bull. Amer. Meteorol. Soc., 79, 213-241, doi: 10.1175/1520-0477(1998)079<0231:STOPAF>2.0.C O;2. [Link]

Lee, C. S., L. R. Huang, H. S. Shen, and S. T. Wang, 2006: A climatology model for forecasting typhoon rainfall in Taiwan. Nat. Hazards, 37, 87-105, doi: 10.1007/s11 069-005-4658-8. [Link]

Liu, J. T., J. J. Hung, and Y. W. Huang, 2009: Partition of suspended and riverbed sediments related to the saltwedge in the lower reaches of a small mountainous river. Mar. Geol., 264, 152-164, doi: 10.1016/j.margeo.20 09.05.005. [Link]

Lloyd, C. D., 2005: Assessing the effect of integrating eleva- tion data into the estimation of monthly precipitation in Great Britain. J. Hydrol., 308, 128-150, doi: 10.1016/j. jhydrol.2004.10.026. [Link]

Mishra, A. K. and V. P. Singh, 2010: Changes in extreme precipitation in Texas. J. Geophys. Res., 115, D14106, doi: 10.1029/2009JD013398. [Link]

Norbiato, D., M. Borga, M. Sangati, and F. Zanon, 2007: Regional frequency analysis of extreme precipitation in the eastern Italian Alps and the August 29, 2003 flash flood. J. Hydrol., 345, 149-166, doi: 10.1016/j. jhydrol.2007.07.009. [Link]

Prudhomme, C. and D. W. Reed, 1999: Mapping extreme rainfall in a mountainous region using geostatistical techniques: A case study in Scotland. Int. J. Climatol., 19,1337-1356, doi: 10.1002/(SICI)1097-0088(199910) 19:12<1337::AID-JOC421>3.0.CO;2-G. [Link]

USGS (US Geological Survey), 1982: Guidelines for Determining Flood Flow Frequency. Bulletin 17-B. Hydrology Subcommittee, USGS, Office of Water Data Coordination: Springfield, VA, USA.

Young, C. B. and B. M. McEnroe, 2006: Updated precipitation frequency estimates for Kansas City: Comparison with TP-40 and HYDRO-35. J. Hydrol. Eng., 11, 206213, doi: 10.1061/(ASCE)1084-0699(2006)11:3(206). [Link]

Zhai, P., X. Zhang, H. Wan, and X. Pan, 2005: Trends in total precipitation and frequency of daily precipitation extremes over China. J. Climate, 18, 1096-1108, doi: 10.1175/JCLI-3318.1. [Link] 